\title{
ACELERAÇÃo, DESACELERAÇÃo, TORTURA SÔNICA E INÉRCIA: TEMPORALIDADES DE PARTIDAS DE FUTEBOL
}

\author{
Pedro Silva Marra
}

\begin{abstract}
RESUMO
Este artigo explora as relações temporais da disputa futebolística, buscando evidenciar como o controle da passagem do tempo e das mudanças de andamento da partida - o que introduz transformações rítmicas a partir de eventos e lances do jogo - tanto por parte dos jogadores quanto da torcida por meio do som são fundamentais para a constituição do resultado esportivo. A pesquisa da qual parte o trabalho visa compreender como torcida e jogo constroem-se mutuamente no espetáculo futebolístico por meio da manipulação de sonoridades, compreendidas como mediações técnicas entre corpos diferentes. Aqui, quatro destas técnicas são delimitadas e exploradas: a aceleração, a desaceleração, a inércia e a tortura sônica. As observações partem de trabalho de campo realizado em partidas do Clube Atlético Mineiro, entre 2008 e 2015, nos Estádios Independência e Mineirão, em Belo Horizonte.
\end{abstract}

\section{Palavras-chave}

Aceleração; desaceleração; futebol; inércia; técnicas sônicas; tortura sônica

\begin{abstract}
This essay explores the time relations in a football match and intends to evidence how controlling the passage of time and the changes in the progress of a match - which introduces rhythmic transformations from events and actions on the match, both by the players and the crowd, by means of the sound - play a fundamental part on the results of that match. This work is derived from a research that aims at comprehending how the crowd and the match are mutually constructed within the football spectacle by means of sonic manipulations that are absorbed as technical interferences between different agents. In this essay, four techniques will be discussed and explored: acceleration, deceleration, inertia and sonic torture. All observations were made through field work in Atletico Mineiro Football Club matches between 2008 and 2015, in the Independencia and Mineirao stadiums, in Belo Horizonte.
\end{abstract}

\section{KEYWORDS}

Acceleration; deceleration; football; inertia; sonic techniques; sonic torture

\section{INTRODUÇÃO}

Cantar em uníssono por toda a partida ou explodir em ruídos intensos e cantos toda vez que o time' tem uma boa chance de marcar um gol? Que grito, palavra de

\footnotetext{
' Nota dos editores: vários termos utilizados neste artigo são específicos do Português falado no Brasil, com correspondências em outros termos específicos utilizados em Portugal (ex. time para dizer equipa, copa para referir campeonato, torcedores para dizer adeptos, torcida organizada como sinónimo de claque de um clube de futebol, goleiro como o nome dado ao guarda-redes, gol como equivalente a golo...).
} 
ordem ou música entoar em cada situação da disputa? Quando deve-se aplaudir ou criticar um jogador ou técnico em campo? Ou ainda "xingar" um árbitro? Estas são controvérsias acerca das melhores formas de torcer no futebol levantadas em pesquisa de campo com gravação de som acerca das sonoridades presentes nas arquibancadas e acionadas pela torcida do Clube Atlético Mineiro, também conhecido como Galo, uma das maiores associações esportivas em Belo Horizonte, Minas Gerais, Brasil. O trabaIho envolveu desenvolvimento de metodologia própria, a partir do registro sonoro de 21 partidas disputadas em torneios diversos, tais como Campeonato Mineiro, Campeonato Brasileiro, Copa Libertadores da América e Recopa Sul Americana e utilizou três gravadores equipados com pares de microfone estéreo dispostos em diferentes regiões da arquibancada. Tais registros eram posteriormente sincronizados entre si e com a narração da referida partida via rádio, o que permitia relacionar os acontecimentos da disputa aos momentos em que a torcida organizava-se em uníssono ou desarticulava-se em balbúrdia. Ao fundo desta discussão, existe uma crença dos amantes do esporte na potência de sua atuação em modular as temporalidades da prática esportiva e o ânimo dos esportistas por meio dos sons que produzem de acordo com o que acontece em campo. Assim, ajudam os atletas a ganhar jogos, seja ao catalisar performances boas ou desastrosas ou ao incentivar certas posturas táticas ou estratégicas de administração do tempo de jogo e do espaço das quatro linhas.

Este artigo apresenta quatro técnicas sônicas - práticas e protocolos de uso do som que se aproveitam das potencialidades de suas materialidades acústicas a fim de realizar determinadas tarefas - ligadas ao agenciamento das temporalidades do jogo de futebol e, portanto, indispensáveis à conquista, construção ou administração dos resultados esportivos. Na aceleração, ritmos marcados, com acentos nos tempos fortes dos bumbos tocados pelas torcidas organizadas², e de andamento veloz são empregados em conjunto com melodias com menos notas e gritadas para imprimir rapidez à equipe em campo. Enquanto isso, a desaceleração consiste no acesso a canções mais lentas e cadenciadas, cujos acentos rítmicos caem em tempos fracos, embalando melodias mais sinuosas a fim de ralentar as ações no jogo.

A continuidade ou intercalação destes movimentos sonoros produz métricas e marcações rítmicas em um nível mais estrutural da partida pontuando transformações temporais fundamentais para a construção ou manutenção do resultado. Dessa forma, na inércia, o fluxo contínuo de canções insistentes da multidão traduz-se em uma atitude incansável da equipe em sua postura ofensiva ou defensiva, esfriando o oponente. Já a tortura sônica é marcada por inesperados e repentinos sons intensos produzidos em um momento específico e importante da disputa quando o oponente já está em dificuldade, tirando vantagem da arquitetura reverberante do estádio. Esta técnica ajudaria a minar a

\footnotetext{
${ }^{2}$ Torcidas organizadas são grupos de adeptos de uma equipe de futebol e são o mais próximo que os grupos torcedores brasileiros chegam das Ultras europeias. Elas, no entanto possuem uma forma de organização social diferente destas últimas, pois as torcidas organizadas possuem uma estrutura altamente hierarquizada, demandam associação formal de seus membros e administram sedes. Os times brasileiros mais importantes costumam contar com o apoio de mais de uma torcida organizada, que, por vezes, se enfrentam em disputas em torno de recursos tais como entradas gratuitas para as partidas.
} 
vontade do adversário, aumentando seu estado letárgico em um momento desfavorável, de forma semelhante à que Cuisick relata acerca do fato da "música desempenhar um papel importante no interrogatório de prisioneiros na guerra contra o terror" (2006, p. 2).

Estas técnicas sônicas estão intimamente ligadas àquilo que acontece em campo na disputa, de tal forma que se torna necessário performar de certas maneiras os repertórios sonoros adequados às situações da disputa. O trabalho identifica diferentes temporalidades da partida e da temporada esportiva interconectados e delineados pelas sonoridades empregadas de acordo com os movimentos dos atletas durante o jogo. Tais dinâmicas entre as práticas de torcer e os eventos do jogo delineiam um saber incorporado dos torcedores sobre como escutar, soar e assistir ao esporte. A partir de uma experiência adquirida em anos de comparecimento ao estádio, as torcidas aprendem como modelar os sons que emitem e desenvolvem maneiras de interferir na disputa por meio destas sonoridades. Desta forma, o artigo identifica, no aparentemente indefinido mar de vozes da arquibancada, culturas sônicas esportivas desenvolvidas, acessadas e transmitidas no calor da disputa esportiva.

\section{TEMPORALIDADES DO FUTEBOL E DO SOM}

Dois tempos corridos de 45 minutos cada, 15 minutos de intervalo. Entre um e cinco minutos de acréscimo por período a fim de compensar os momentos em que a bola não está rolando em campo. Temporadas anuais nas quais se distribuem ao longo dos meses campeonatos com fórmulas de disputa diversas. Para cada regulamento, diferentes sequências de resultados podem ser mais definidoras: vitórias seguidas - ou sua falta - no momento certo podem embalar uma campanha vitoriosa - ou frustrante - em torneios de pontos corridos, enquanto a administração de resultados e placares é essencial nas copas organizadas em torno de partidas eliminatórias. Tal sazonalidade confere importância a um jogo: se vale uma posição de destaque na tabela, ou um título; se o campeonato já está decidido e o compromisso esportivo serve apenas para cumprir tabela. Estes são alguns dados temporais com os quais os atores envolvidos na prática futebolística devem lidar a todo momento da disputa, o que evidencia que um controle apropriado do tempo de jogo se torna essencial para a conquista da vitória e de campeonatos por parte das equipes.

Diferentes trabalhos abordam a questão da dimensão temporal da prática esportiva, seja no que diz respeito às diversas formas como acontece a cronometragem e suas implicações na eficiência, aproveitamento e dinâmica das ações dos atletas ao longo da disputa (Wisnik, 2008); às diferentes qualidades perceptivas da passagem do tempo em sua prática e expectatorialidade de acordo com a situação do confronto no esporte em geral (Gumbrecht, 2007) ou no futebol em específico (Franco Júnior, 2007); ou ainda no que diz respeito às formas como os meios de comunicação de massa lidam com estes diferentes regimes temporais (Telles, 2014; Telles \& Silva, 2014). Por meio deste levantamento acerca do assunto, percebemos pelo menos três eixos aos quais se articulam as dinâmicas temporais no futebol: a duração da disputa e os momentos da partida; as 
ações dos atores - jogadores, técnicos, torcedores, arbitragem - em campo; e a sequencialidade e relevância das partidas em uma temporada.

Em primeiro lugar, a longa duração de cada período da partida e o fato de a contagem do tempo não se interromper junto com o jogo criam dinâmicas de urgência e ociosidade cuja administração transcende a questão do preparo físico necessário à prática esportiva e se torna um ponto fundamental para a delimitação da estratégia e tática de jogo de uma equipe (Wisnik, 2008). Assim, o controle da posse de bola muitas vezes é tomado como um parâmetro para se medir o domínio das ações por um time na análise jornalística: manter a bola nos pés por longo período pode ser um indício de uma melhor performance, já que tal atitude, em princípio, reduz o risco de sofrer e aumenta o de marcar gols.

Tal fato delineia também atitudes diferentes das equipes ao longo da duração da partida de acordo com o que acontece em campo. Marcar sob pressão nos 15 minutos iniciais ou trocar passes estudando o adversário no mesmo período a fim de aproveitar o melhor momento de atacar? Manter a pressão após assinalar um gol ou recuar esperando uma oportunidade de pegar a defesa adversária desprevenida em contrataque? Deixar o tempo passar nos minutos finais quando o resultado é satisfatório por meio da manutenção da bola no campo adversário ou da catimba33, ou sair desesperadamente rumo ao ataque, com bolas alçadas na área, quando a busca pela vitória é imprescindível? Tais formas de gestão do tempo da partida delineiam formas de jogo que identificam não só estilos de equipes locais ou de seleções nacionais (Gumbrecht, 2014), mas também períodos históricos do futebol e suas respectivas ocupações predominantes de espaço pelos atletas em campo (Wilson, 2008). Poderíamos nos alongar aqui indicando a articulação entre o aumento da velocidade do jogo e a necessidade de marcação forte que caracteriza o esporte nos anos 90 e os esquemas 4-4-2 e 0 3-5-2, ou as táticas mais contemporâneas de manutenção da posse de bola por meio da troca de passes ao 4-1-41 ou 4-2-3-14 (Almeida, Lauria \& Lima, 2016).

Tal variedade e articulação de temporalidades desce ao nível mais micro-estrutural da partida, propondo percepções e reações temporais diversas para cada agente envolvido no jogo. De um lado, Hilário Franco Júnior (2007) destaca que cada função tática do futebol lida com tempos discursivos diferentes: enquanto a defesa trabalha no condicional, buscando prever e antecipar os movimentos do adversário; a criação de jogadas lida com o futuro, no sentido que procura produzir possibilidades de definição da partida por meio de gols; e o ataque lida com o presente, pois tenta realizar estas virtualidades a cada momento em que se apresentam. O campo de estudos de motricidade busca avaliar tais

\footnotetext{
3 Nota dos editores: catimba é um termo especificamente brasileiro, utilizado no contexto desportivo para designar um recurso antidesportivo (ex. gastar tempo desnecessariamente durante um jogo).

4 Uma das formas de se expressar o posicionamento e distribuição dos jogadores em campo, o que delineia esquemas táticos, se dá pela escrita em números separados por hífens. Cada um dos números significa a quantidade de jogadores situados em um setor do campo, seja a defesa, o meio de campo ou o ataque. O goleiro é excluído nessa contagem, pois se pressupõe que ele é sempre o último jogador. Dessa forma, 4-4-2 implica em uma disposição de atletas no gramado em que quatro jogadores localizam-se na defesa, outros quatro no meio de campo e dois no ataque. No 4-2-3-1 - uma variação moderna do 4-3-3 - a linha média é subdividida em dois setores, o meio-defensivo e o meio-ataque. Assim, nesse esquema tático, temos quatro defensores, dois meio campistas defensivos, três meio campistas ofensivos e um centroavante.
} 
questões no nível dos movimentos específicos e dos padrões de jogo (Machado, Barreira \& Garganta, 2013) e da ocupação tática espaço-temporal (Travassos, Monteiro, Duarte \& Marques, 2015), a fim de avaliar a eficácia de determinados padrões de jogo.

Técnicos, torcedores e arbitragem lidam a todo momento com passado, presente e futuro. Estes últimos não só devem tomar decisões imediatas sem se afobar ${ }^{5}$ e considerando resoluções tomadas em situações de jogo semelhantes anteriores, mas também intervêm diretamente na velocidade e andamento da disputa, de acordo com o critério que utiliza. Por exemplo, na marcação de faltas - todo encontro físico entre atletas será punido, ou o jogo correrá mais livremente? Os primeiros devem avaliar, a cada partida, o histórico recente de atuações do adversário, bem como avaliar no presente suas atitudes iniciais, a fim de intervir no curso de ações em disputa de modo a corrigi-las face a um objetivo futuro de vitória. Finalmente, a torcida não só se envolve em sua habitual rivalidade e jocosidade com o adversário que leva em consideração os confrontos anteriores com os oponentes, mas também envolve-se em ações durante o jogo visando avisar os jogadores de possibilidades que se apresentam ao longo das ações, ou antever lances futuros na esperança de que se realizem mais facilmente, bem como punir sonoramente um eventual erro dos atletas da equipe do coração ou caçoar o equívoco adversário. Destacamos ainda a percepção temporal que se comprime ou distende para todos estes atores do futebol de acordo com lances capitais da partida (Gumbrecht, 2007), como a cobrança de um pênalti decisivo, ou os últimos minutos de uma partida de final de campeonato.

Mas o futebol também apresenta durações que se estendem para além do tempo de uma única partida. Muitas vezes, a equipe que se torna campeã ao final de um torneio é aquela que apresenta maior regularidade jogo a jogo, ou a que vence confrontos com adversários diretos na disputa pelo título, ao invés daquela que desempenhou uma performance melhor ou mais bonita em disputas específicas. Assim, a sequência de resultados delimita momentos e períodos mais ou menos eufóricos para os times e torcida, que se aproveitam desta mais-valia anímica proporcionada por tal momento de graça a fim de manter o alto desempenho. Inclusive, as agremiações que geralmente sagram-se campeãs de torneios de pontos corridos são exatamente aquelas que conseguem embalar mais de uma série de vitórias seguidas, intercaladas com poucos empates e derrotas. Esta dinâmica tem sua parte inclusive no fluxo de torcedores aos estádios para assistir às partidas e na sua atitude para com os jogadores. Portanto, uma série de derrotas pode, por exemplo, - de acordo com o momento do campeonato - induzir protestos contra o mau desempenho em campo, no início do torneio; ou catalisar a lotação do estádio na tentativa de interromper a série de infortúnios e empurrar o time contra um possível rebaixamento.

Mais do que qualidades temporais diversas delineadas por tais dinâmicas, o que toma a frente e que merece destaque para o andamento deste trabalho é que tal variação e articulação de temporalidades produz ritmos diferentes para a prática do futebol. Para

${ }^{5}$ Nota dos editores: afobar é igualmente uma expressão brasileira pouco comum em Portugal, que quer dizer causar afobação ou atrapalhação. 
além da ideia de ritmos longos ou curtos a que se refere Franco Júnior (2007), interessa aqui a capacidade de cada um deles em embalar, sincronizar ou harmonizar os corpos dos agentes envolvidos no jogo, bem como o papel que a sua quebra, interrupção ou mudança podem ter na transformação do andamento dos lances da partida.

Henri Lefebvre (2013) destaca que os ritmos constituem-se a partir de repetições e diferenças que marcam medidas e frequências nas quais os eventos reaparecem ou divergem. $\mathrm{O}$ autor busca compreender as formas como a vida social se imprime sob e contagia os sujeitos a partir das repetições e diferenças articuladas nos ritmos da sociedade, explorando, por exemplo, a forma como os ritmos militares disciplinam corpos no exército, os fluxos midiáticos contemporâneos nos acostumam à imediaticidade do cotidiano ou como as variações nas marés oceânicas ou de mares interiores imprimem uma vida urbana mais intensa ou regulada em cidades europeias à beira do Mediterrâneo ou do Oceano Atlântico.

Lefebvre (2013) percebe o ritmo como uma manipulação de tempo e espaço de tal forma que as mudanças sociais de grande impacto produzidas pelas revoluções estão diretamente ligadas a transformações rítmicas em que uma pulsação anterior é substituída por uma nova que deve ser incorporada pelos agentes envolvidos. Acreditamos que tal perspectiva se torna de grande valia para o nosso trabalho, na medida em que abre brechas para pensar como o andamento dos rumos de uma partida, campeonato ou temporada pode se alterar. Afinal, um zagueiro ${ }^{6}$ só aparece no ataque em condições de surpreender o adversário e marcar um gol se ele muda o registro temporal necessário para o desempenho de cada uma das funções. O técnico obtém maior visibilidade acerca de sua participação no jogo quando realiza uma escalação inesperada ou uma substituição que transforma o ritmo da equipe ou da disputa. Ou ainda a torcida se apresenta definidora a partir da variação de cânticos que mudam a cadência dos jogadores ou da sua interrupção em caóticos e intensos ruídos que podem desnortear um adversário resistente mas que mostra-se grogue após um lance de perigo.

Tal interconexão entre os sons da arquibancada e a performance dos jogadores parece encontrar uma ligação nas características temporais que usualmente definem as sonoridades. Afinal, uma de suas definições correntes baseia-se em sua natureza ondulatória, a partir de suas características vibratórias que implicam na sua periodicidade, ou seja na repetição em tempos determinados de estados de movimento específicos. Assim, uma boa parte do vocabulário utilizado para descrever as sonoridades - agudo, médio, grave, lento, rápido, cadenciado, marcado, etc - remete ao plano das frequências. Este parâmetro acústico define não só o recorte de tempo em que ocorrem tais reiterações de repouso, compressão e dilatação de pressão do meio em que o som caminha, mas também à velocidade e intervalos com os quais diferentes vibrações se sucedem ou repetem em uma determinada duração. Neste sentido, a composição de melodias, andamentos e ritmos são formas de manipulação das possibilidades temporais do mundo sônico.

\footnotetext{
${ }^{6}$ Nota dos editores: zagueiro é um termo brasileiro para nomear um jogador que integra a linha de defesa, vulgarmente designado em Portugal como um defesa.
} 
Tais formas sonoras aparecem na vida social para além do plano musical ou da dança, modulando ritmos corporais em diversas práticas sociais. Tia DeNora (2000), em trabalho etnográfico acerca dos usos cotidianos da música, mostra como esta forma cultural é empregada para regular diversas atividades humanas, inclusive a prática esportiva. Em seu trabalho de campo em aulas de ginástica aeróbica, a pesquisadora observa como a correta escolha e encadeamento de peças musicais - em termos não só da escolha de repertórios melódicos, rítmicos e de andamentos apropriados para cada momento da sequência física, mas também de sua correta ordenação - lançam e conduzem seus praticantes no exercício, a ponto de escolhas musicais equivocadas do instrutor atrapalharem o rendimento dos alunos. Desta forma, uma aula de ginástica sempre termina com o conjunto de composições de andamento mais lento de forma a coincidir com o momento de relaxamento. O seu início é ligeiramente mais veloz que o seu final, caminha acelerando até a metade de sua duração quando são realizados os movimentos de alto impacto da seção e enfim ralenta novamente. Os ritmos metronímicos e marcados e melodias simples e etéreas também embalam a seção. "A música aqui é uma mediação que descreve 'como' - como mover, como pensar, como incluir, como começar, como terminar, como misturar" (DeNora, 2000, p. 93).

\section{SOM E AGÊNCIA: TÉCNICAS SÔNICAS}

Técnicas sônicas são práticas e protocolos de uso do som que se aproveitam de potencialidades presentes em suas materialidades acústicas a fim de realizar determinadas tarefas. As sonoridades apresentam certas características, ou parâmetros, tais como intensidade (volume), frequência (ritmos, melodias, durações, andamentos e timbres) e espacialidade (reverberação, direção, alcance), que favorecem sua apropriação para a composição de certos fazeres e de diferentes sensibilidades. A agência sonora constitui-se a partir de manipulações de todos estes parâmetros acústicos de eventos audíveis simultaneamente. Assim, ao invés de perguntar sobre o significado de um som, este artigo investiga sobre o que é possível realizar com ele. Esta mesma preocupação guia o trabalho de Tia DeNora que mapeia os usos cotidianos da música pelos sujeitos com vista a alcançar certos objetivos, tais como mediar interações sociais, auto-regular afetos, compor subjetividades, rechaçar riscos e "insinuar e inspirar fé" (DeNora, 2000). A autora, neste sentido, trata a música como uma tecnologia, na medida em que as vibrações musicais implicam uma agência compartilhada entre a música e os seus usuários que a manipulam como a um dispositivo: nem o som é capaz por si só de produzir determinados efeitos, nem qualquer música pode ser acessada de qualquer maneira para alcançar os resultados pretendidos em sua composição.

Esta pesquisa propõe uma pragmática do som a fim de investigar como os torcedores de futebol manipulam parâmetros acústicos de vibrações sonoras, em seu soar a fim de conquistar realizações específicas. Ao lidar com a forma como empregam certos ritmos ou melodias; percutem objetos específicos; as situações e objetivos dos torcedores ao gritar mais intensamente, em diferentes entonações, timbres, prosódias; ou 
como apropriam-se de características acústicas do local que habitam permite delinear um repertório (Faukner \& Becker, 2009) de técnicas sônicas a partir do qual participam da construção do espetáculo esportivo. Este caminho pode auxiliar a compreensão do poder das sonoridades empregadas pela torcida em catalisar a aceleração e lentidão das ações e/ou a manutenção ou transformação de velocidades e ritmos de um time ao longo de uma partida.

A ideia de que as sonoridades carregam potências e possuem agências remete a uma dualidade do mundo audível que pode ser percebido tanto como texto que produz sentidos, quanto como força que age diretamente sobre os corpos de agentes. Martin Daughtry aponta este caminho em estudo sobre os sons da guerra no qual ressalta que neste contexto os "estímulos sensórios atacam corpos embebidos em adrenalina, criando estados afetivos extremos de intensidade e vulnerabilidade, estímulo e degradação, agressão e medo" (2014, p. 25). O autor argumenta que ao duplo caráter de força e signo das vibrações sônicas correspondem recepções gnósticas ou cognitivas e drásticas ou hápticas. Assim, além de produzir sentidos, o mundo sonoro produz impacto sobre os corpos, já que o som tem tamanho ao ocupar um espaço equivalente à área em que é escutado; possui massa na medida em que exerce pressão sobre a pele numa interface entre o audível e o tátil, sobretudo no que diz respeito às frequências graves; bem como apresenta tanto direcionalidade - objetivando um alvo - quanto omnidirecionalidade voltando-se também a seu emissor. Algo que soa sempre pressupõe alguém que escuta e vibra em simpatia, de acordo não só com aquilo que se delineia pelas sonoridades em questão, mas também com a disponibilidade corporal dos sujeitos imersos em uma cultura. Neste sentido, soar - produzir sons - é sempre também escutar - captá-los: o evento sonoro que se percebe como uma única entidade é na verdade "uma sinfonia de vibrações dispersas em simpatia" (Daughtry, 2015, p. 164).

Em contextos sensíveis e audíveis extremos, como a guerra - com seus sons repentinos e muito intensos em meio ao silêncio do campo de batalha - ou eventos esportivos - onde multidões produzem uma sonoridade intensa e incessante - tais propriedades hápticas tomam a frente em relação ao aspecto cognitivo dos sons pois são "direcionados aos corpos o que lhes revela como frágeis e vulneráveis à violência com as quais ressoam" (Daughtry, 2014, p. 32). Nestas situações, as sonoridades colonizam os corpos tornando-se capazes de suspender a racionalidade dos agentes e modular suas ações de acordo com aquilo que suas características acústicas delineiam. Tal estado de exasperação auditiva ativa também a memória, possivelmente retornando posteriormente quando sonoridades semelhantes são novamente acessadas. Pensar as sonoridades nestes termos aponta para um quadro teórico que lida com o som como afeto no qual os corpos imprimem e deixam-se imprimir efeitos uns pelos outros a partir de afinidades que se desenrolam entre os planos físico-químico, biológico e cultural. Assim, as sonoridades conformam-se como "entrada acústica para campos afetivos" (Thompson \& Biddle, 2013, p. 16). Submetidos a tais condições por longos períodos, os corpos desenvolvem 
habilidades sofisticadas de escuta (...) [que habilitam os agentes] a engajar-se em um tipo de hermenêutica cultural e topograficamente modulada (...) Neste sentido, o som ambiente serviu como uma fonte profundamente democrática de informação tática para aqueles que possuem a habilidade de decodifica-la. (Daughtry, 2014, p. 26)

Adquirir estas habilidades de decodificação e assim domar as forças sonoras com fins a redirecioná-las, por meio de técnicas sônicas, tendo em vista certos fins é um processo de pedagogia e formação do sensível que no caso do futebol não é sistematizado. Não existe nenhum livro, oficina, ou curso no qual as pessoas aprendem como apoiar o time. Este saber é adquirido por meio de uma longa experiência em assistir partidas de futebol, no qual os torcedores aprendem não só os eventos sônicos que devem emitir, mas também os momentos corretos em que cada som é necessário e que características acústicas devem ser empregadas nesta agência em certa situação. Portanto, são usualmente acessados pelos torcedores no estádio no calor do momento, o que torna difícil relacionar uma racionalidade funcional a suas ações.

A fim de adquirir estas habilidades, é necessário que os indivíduos atinjam uma sintonia fina com o jogo, na qual sua atenção sincroniza-se com a "aparição de algo que está aparecendo", formulando uma percepção estética que "ancora a consciência (que é muito receptiva a abstrações, antecipações e retrospectivas) através de períodos de um intenso apelo à presença" (Seel, 2014, pp. 26-27). Tal conexão remete a um estado perceptivo de atenção corporificada, que é usualmente "não proposital, não cognitiva, uma orientação e expectativa animalesca voltada ao ambiente físico" (DeNora, 2000, p. 84) e que intimamente conecta suas habilidades de ler visualmente as táticas e estratégias do jogo, prever lances possíveis dos atletas, escutar as canções, ritmos, gritos e palavras de ordem emitidos pelo público, e soar de acordo ou contra esta informação perceptiva.

\section{ACEleração e deSACEleração}

As duas primeiras técnicas sônicas que concatenam as dimensões temporais das partidas de futebol e das sonoridades propostas neste artigo são a aceleração e a desaceleração. Na primeira, ritmos rápidos e marcados, com acentos nos tempos fortes dos bumbos tocados pelas torcidas organizadas, são empregados em conjunto com melodias de poucas notas e gritadas para imprimir velocidades rápidas à equipe em campo. Enquanto isso, a segunda consiste no acesso a canções mais lentas e cadenciadas, cujos acentos rítmicos também caem em tempos fracos, embalando melodias com mais notas e sinuosas a fim de ralentar as ações no jogo. Importante notar que o instrumento utilizado para marcar e dar métrica a tais ritmos é grave, porção do espectro audível mais bem percebido pela pele, o que acentua os aspectos hápticos destas dinâmicas.

Algumas canções empregadas para a aceleração pela torcida do Clube Atlético Mineiro, objeto de investigação deste artigo em pesquisa realizada entre 2008 e 20167,

\footnotetext{
7 Uma descrição e reflexão acerca dos procedimentos metodológicos da pesquisa pode ser encontrado em Marra, 2015.
} 
são Vai pra cima deles, Galô; Ganhar [o título em disputa], e vamos, vamos Galo; Atlético Mineiro, e da-Ihe, da-Ihe galo, Olê, olê, olê e O Galo é o time da virada. Todas estas peças musicais são compostas por poucos versos e melodias muito similares que empregam poucas notas. A paródia da marchinha de carnaval Mulata Bossa Nova também produz aceleração, sendo entoada uma ou duas vezes a plenos pulmões usualmente quando o Galo quase marca. Já para a desaceleração utiliza-se em sua maioria canções e temas conhecidos, como Valeu a pena, do grupo carioca O Rappa; Samba rock do molejão, do conjunto de pagode homônimo; uma paródia de Mas que nada, de Jorge Ben Jor; a trilha sonora do filme A ponte do rio Kwai; e a composição popular norte americana When the saints go marching in. Enquanto as composições estrangeiras são acessadas apenas em seus refrões, as nacionais utilizam toda a letra da composição e são cantadas não mais do que duas vezes seguidas.

Durante a pesquisa de campo realizada nos estádios Independência e Mineirão, percebemos que a técnica de aceleração sempre é acessada no início da partida - sobretudo quando um determinado número de gols é necessário para garantir a classificação em partidas em fases eliminatórias de campeonatos. Também é empregada quando os visitantes abrem o placar. Nestas ocasiões, a torcida sempre responde ao acontecido com a canção $O$ galo é o time da virada, composta por quatro versos simples, dois deles constituídos apenas por onomatopeias. Outras canções na mesma toada são acessadas a fim de manter a velocidade rápida do jogo, até que os atleticanos virem o placar. Um exemplo desta dinâmica aconteceu em partida contra o Independiente Santa Fé da Colômbia, disputada em 12 de fevereiro de 2014 e válida pela fase classificatória da Copa Libertadores daquele ano. Na ocasião, os colombianos abriram o placar e a torcida respondeu ao placar adverso com ritmos rápidos e melodias simples até que a virada fosse obtida, ao final da partida. Nesse momento, as arquibancadas entoaram Valeu a pena enquanto saíam do estádio marcando uma desaceleração após intensa rapidez. As outras paródias citadas acima também são mobilizadas durante outros jogos quando o placar já está construído, ou seja quando a vantagem de gols conquistada garante uma vitória tranquila sobre o adversário, e as ações em campo já não despertam tanto interesse dos torcedores. Ainda registramos a utilização desta técnica em casos em que a partida caminha para seu final e o adversário não parece ter fôlego para alterar o resultado. Nestes momentos, muitas vezes torna-se necessário esfriar as ações do oponente que ainda busca reduzir a desvantagem ou o empate.

O controle da velocidade do jogo, e, por conseguinte das dimensões temporais das partidas de futebol por meio de sonoridades lentas ou rápidas parece casar-se de maneira íntima com as estratégias de jogo adotadas pelo Atlético Mineiro no período pesquisado. Entre 2012 e 2016 a diretoria do clube conseguiu manter a base de jogadores, e com isso, estabeleceu um padrão de jogo baseado no esquema 4-2-3-1, em que procura manter sempre a posse de bola no campo adversário em busca do ataque, seja por meio da troca de passes e movimentação, seja por meio de bolas alçadas na área ou passes longos da defesa diretamente ao ataque que será disputada por um centro-avante alto e 
forte visando repassá-la a um ponta de velocidade ${ }^{8}$ que penetra na diagonal. Se tal postura no gramado visa a sufocar o adversário, obrigando-o a manter-se na defesa, apresenta o ponto fraco de dispor a defesa muito adiantada, o que aumenta a distância entre a última linha de defensores e o goleiro, oferecendo, portanto, o contra-ataque ao oponente. O antídoto para este calcanhar de Aquiles é a rápida recomposição da defesa, o que nem sempre acontece de maneira eficiente. É nesse sentido que uma grande velocidade se faz necessária no início da disputa: um placar favorável construído rapidamente permite à equipe atleticana explorar o contra-ataque e assim administrar a vantagem construída. Com a vitória assegurada, a desaceleração é empregada com fins a deixar o time mais relaxado com relação às tarefas ofensivas e consequentemente menos exposto defensivamente, já que este é um dos pontos fracos do esquema tático escolhido.

\section{INÉRCIA E TORTURA SÔNICA}

Se a aceleração e a desacelaração se mostram eficazes como técnicas ligadas a momentos específicos do jogo, em um eixo sincrônico, em um recorte temporal mais logo e diacrônico, a repetição de estados de rapidez ou lentidão delimita uma outra técnica sônica, a inércia. Nesta forma de manifestar apoio ao time, a torcida busca cantar incessantemente o maior tempo o possível - alcançando o uníssono por vezes - mantendo-se, portanto, em movimento no mesmo sentido, até que um evento inesperado no jogo a faça mudar de atitude. A analogia aqui é com o princípio que rege a primeira lei da dinâmica e que estabelece que os corpos tendem a manter-se parados ou em movimento, a não ser que o equilíbrio de forças que atuam sobre ele se desfaça, o que inicia uma trajetória, muda sua direção ou o cessa por completo. A intenção é produzir uma espécie de transe, que embala a equipe em sua postura ofensiva e rápida - ou defensiva e lenta, caso seja ela a sofrer a pressão adversária. Os torcedores, neste sentido, procuram manter o fôlego em suas emissões sonoras a fim de, ao mesmo tempo, "emprestá-lo" aos atletas em campo e "retirá-lo" do oponente. Acuados pela ação do mandante e pela insistência sonora do público, o visitante apresenta dificuldades para respirar, sucumbindo metaforicamente por asfixia, caso a técnica seja bem sucedida.

$\mathrm{Na}$ grande maioria dos jogos registrados no trabalho de campo, a inércia empregada no início de jogo tem um caráter de aceleração, sobretudo na forma como a técnica sônica é utilizada pela Galoucura, principal torcida organizada do Galo. Quando a equipe entra em campo, os torcedores tradicionalmente entoam o hino e em seguida gritam ou cantam versos com os nomes dos jogadores escalados. Outras músicas muito populares entre os amantes da equipe mineira neste momento são aquelas que denotam o domínio territorial do Estádio Independência, como o Vou ficar de arquibancada pra sentir mais emoção. Após o apito inicial, as arquibancadas iniciam o processo de aceleração descrito anteriormente e o grupo uniformizado puxa as melodias do repertório musical que compõem a técnica da aceleração. O procedimento dura vários minutos, ou até que

\footnotetext{
${ }^{8}$ Nota dos editores: centro-avante é a expressão utilizada no Brasil como correspondente de avançado-centro em Portugal. Já ponta de velocidade é equivalente a ponta-de-lança.
} 
um evento importante - um lance de perigo, um gol, uma falta controversa - aconteça no gramado. Por vezes, o restante da arquibancada entra no transe sugerido pela repetição prolongada, ecoando a Galoucura.

Os 12 minutos iniciais da partida válida pelas oitavas de final da Copa do Brasil, entre os Mineiros e o Palmeiras, de São Paulo, exemplificam bem a dinâmica. Nesta ocasião, a Galoucura passou este tempo cantando apenas dois versos, o "Vai pra cima deles Galo" e o "Dá-lhe Galo", acessando a canção Mulata bossa nova apenas uma vez, quando o Palmeiras chega com perigo ao gol atleticano. Neste momento, a torcida alviverde presente em pequeno número se torna audível na parte alvinegra do setor das arquibancadas que ocupava devido a um lance de perigo contra o Galo: torna-se necessário, então cantar alto para silenciar o adversário. Em meio à cantoria, irrompem em todos os setores, ao sabor dos acontecimentos, outras sonoridades como vibrações, xieiras, xingamentos, vaias, incentivos, comentários, ordens e reclamações. De tempos em tempos toda a arquibancada sintoniza-se com o som que vem da torcida organizada que é sempre ouvida ao menos em segundo plano em todos os setores até que o primeiro gol da partida sai em cobrança de escanteio ${ }^{9}$. A inércia cumpre seu papel, insistindo em um movimento de aceleração até ao momento em que o gol se contretiza.

Então, instala-se uma ensurdecedora balbúrdia - os gravadores não suportam a grande intensidade sonora e distorcem o registro - em comemoração. Os instrumentos cessam o batuque e o que se ouve é uma massa sonora resultante de gritos e vibrações individuais e desorganizados que compõem um indefinido mar de vozes. Quinze segundos após, a Galoucura se reorganiza e entoa a palavra de ordem Uh uhu é Galoucura e em seguida o hino do clube, que sempre é ecoado em toda a arquibancada após o gol. Ao fim, como é de praxe, a torcida canta Galoôô sobre acompanhamento melódico Gospel norte americano de When the saints go marching in. O gol, neste sentido, marca um corte no fluxo temporal tanto da partida quanto das sonoridades emitidas pelas arquibancadas, instituindo um evento que transforma seu andamento e constituindo, portanto, um ritmo.

Assim, à inércia articula-se a tortura sônica, que no caso do futebol consiste na produção sonora intensa e momentânea em momentos chave do jogo, como quando a bola acerta a trave, o goleiro adversário realiza uma defesa difícil, numa sequência de cobranças de escanteio, ou no caso de uma cobrança de falta perigosa. A tortura sônica manifesta-se por vezes de maneira desconexa em gritos, urros, toques em instrumentos de percussão e objetos do estádio como cadeiras, grades e vigas de sustentação que resultam em uma desorganizada e ensurdecedora balbúrdia; em outras ocasiões em uníssono, entoando breves canções de motivação ou palavras de ordem facilmente reconhecíveis pelas arquibancadas. O termo é emprestado do trabalho de Suzanne Cuisick (2006) que investiga as formas como a música e o som é utilizado como arma ou em práticas que são consideradas tortura pois desrespeitarem protocolos internacionais de direitos humanos, como no interrogatório de prisioneiros de guerra no combate

${ }_{9}$ Nota dos editores: escanteio é o termo brasileiro para designar uma falta cometida por um jogador que atira a bola para lá da linha de fundo (canto). 
norte americano ao terrorismo. Neste último caso, indivíduos são submetidos a longa exposição a material musical descrito como irritante ou ofensivo, em alta intensidade e em condições ambientais desfavoráveis, como quartos escuros e úmidos, produzindo uma forma de tortura sem contato direto - e portanto sem deixar marcas visíveis - que apresenta uma eficácia maior no objetivo de induzir estados psicológicos de desorientação sensorial e quebra do ego do que, por exemplo, a privação de sono e comida, ou a violência física.

No caso do futebol, o inesperado, disruptivo e forte ruído oriundo das arquibancadas a partir de eventos desfavoráveis ao adversário impactariam seus corpos e produziriam um estado de desatenção em momentos em que a concentração é chave para o bom desempenho atlético. Em contraposição, a sonoridade triunfante dos urros de alegria, canções e palavras de ordem vitoriosas inflariam os egos dos atletas da equipe do coração, aumentando o seu ímpeto e até mesmo antevendo o sucesso pretendido no próximo lance.

O momento do gol, portanto, exemplifica ao máximo a técnica da tortura sônica. Retomando o relato da partida acima entre o Galo e o Palmeiras percebemos como a estratégia surte efeito na sequência do jogo. A euforia do público contagia os jogadores da equipe mineira e termina por abater os palmeirenses - que já necessitavam de uma vitória longe de seus domínios para se classificar à fase seguinte: cinco minutos depois do primeiro gol, o Atlético marca pela segunda vez, dando números finais ao confronto. A partir daí as arquibancadas lançam-se até ao final da disputa em uma inércia de desaceleração, encadeando as músicas mais lentas, de melodia sinuosa e ritmo cadenciado do repertório desta técnica sônica. A Figura 1 mostra uma visualização dos 12 primeiros minutos da partida em questão, evidenciando estas marcas e quebras de ritmo introduzidas no fluxo sonoro da partida pela alta intensidade da tortura sônica.

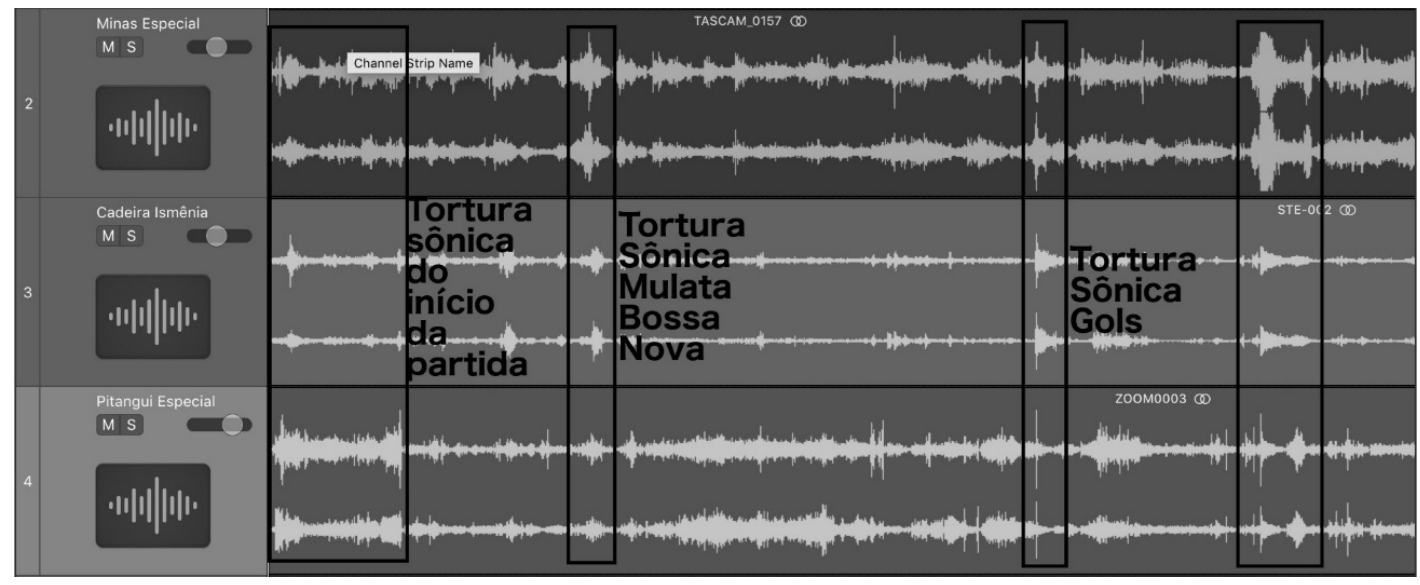

Figura 1: Forma de onda dos 12 primeiros das gravações realizadas no jogo Atlético x Palmeiras. Os retângulos evidenciam momentos de tortura sônica

Outros exemplos de repertórios acessados na dinâmica de tortura sônica são o grito de Uhhhhh, as vibrações intensas e a canção Mulata bossa nova, entoada quando um ataque passa perto do gol, a bola atinge a trave, ou a arbitragem toma uma decisão 
favorável ao Galo. Além disso, xieiras, xingamentos e palavras de ordem como Ei [jogador adversário, instituição ou juiz], vai tomar no cu e Bicha após um erro do adversário, da arbitragem ou de atleta da equipe do coração, uma chance de gol do oponente, ou quando o goleiro rival cobra o tiro de meta também são entoados com vista a realizar a mesma ação. No caso específico do grito de Bicha durante o tiro de meta adversário, produz-se um uníssono nem sempre bem definido, mas de grande intensidade que marca uma situação específica no fluxo da partida. O resultado é a interrupção do andamento dos cantos do público provocado pelos lances em campo, o que introduz uma mudança rítmica tanto na performance da torcida, quanto dos atletas no gramado.

Nem sempre esta quebra temporal se mostra benéfica para o Galo. O grito de "Bicha" - que se tornou moda entre as torcidas em todo o Brasil depois da sua introdução no país por torcedores mexicanos durante a Copa do Mundo de 2014 - se mostra condenável, por exemplo, para além de sua conotação machista e homofóbica. Ele raramente é eficaz em seu intuito de atrapalhar a reposição adversária do tiro de meta, mas quase sempre desarticula a arquibancada, produzindo um breve silêncio após sua emissão. Retomar a inércia em seguida pode tornar-se difícil, pois a multidão se vê confusa e encontra uma breve dificuldade em decidir sobre o que cantar. A Tabela 1 resume as quatro técnicas sônicas trabalhadas neste artigo, explicitando as situações de jogo, as características acústicas dos sons empregados e o repertório de canções predominantes.

\begin{tabular}{|c|c|c|c|}
\hline TÉCNICAS SÔNICAS & SITUAÇÃO DE JOGO & $\begin{array}{c}\text { CARACTERÍSTICAS } \\
\text { ACÚSTICAS DOS SONS } \\
\text { EMPREGADOS }\end{array}$ & $\begin{array}{l}\text { REPERTÓRIO DE CAN- } \\
\text { ÇÕES PREDOMINANTES }\end{array}$ \\
\hline Aceleração & $\begin{array}{l}\text { Início da partida, após lance } \\
\text { de perigo, necessidade de } \\
\text { construir, virar, ou segurar } \\
\text { um resultado apertado com o } \\
\text { adversário exercendo pressão }\end{array}$ & $\begin{array}{l}\text { Ritmos Rápidos e mar- } \\
\text { cados (acento do surdo } \\
\text { nos tempos fortes) }\end{array}$ & $\begin{array}{l}\text { Vai pra cima deles Galô } \\
\text { Ganhar [o título em dispu- } \\
\text { ta], e vamos, vamos Galo } \\
\text { Atlético Mineiro, e da-lhe, da-lhe galo } \\
\text { O Galo é o time da virada } \\
\text { Paródia de Mulata Bossa Nova }\end{array}$ \\
\hline Desaceleração & $\begin{array}{l}\text { No meio de partidas com resul- } \\
\text { tado e número de gols alcança- } \\
\text { dos, necessidade de adminis- } \\
\text { trar um resultado, ao final de } \\
\text { uma partida ganha facilmente, } \\
\text { necessidade de "esfriar" o jogo. }\end{array}$ & $\begin{array}{l}\text { Ritmos Lentos e cadencia- } \\
\text { dos (surdo pontua tempos } \\
\text { fracos ou contratempos) }\end{array}$ & $\begin{array}{l}\text { Valeu a pena (O Rapa) } \\
\text { Samba rock do molejão } \\
\text { Paródia de Mas que } \\
\text { nada (Jorge Bem) } \\
\text { Paródia da trilha do fil- } \\
\text { me A ponte do rio Kwai } \\
\text { Paródia do tema popular When } \\
\text { the saints go marching in }\end{array}$ \\
\hline Inércia & $\begin{array}{l}\text { No fluxo do jogo, entre } \\
\text { momentos chave da disputa } \\
\text { como gols, faltas, riscos de } \\
\text { alteração do placar, etc. }\end{array}$ & $\begin{array}{l}\text { Encadeamento ininterrupto } \\
\text { das canções que compõem } \\
\text { o repertório da aceleração e } \\
\text { da desaceleração, de forma } \\
\text { a desencadear um estado } \\
\text { semelhante ao transe. }\end{array}$ & $\begin{array}{l}\text { Os repertórios da aceleração } \\
\text { e da desaceleração, à exces- } \\
\text { são de Mulata bossa nova. }\end{array}$ \\
\hline Tortura sônica & $\begin{array}{l}\text { Logo após momentos chave da } \\
\text { partida, como gols, faltas, ris- } \\
\text { cos de alteração do placar, etc. }\end{array}$ & $\begin{array}{l}\text { Breves canções, gritos } \\
\text { e outras sonoridades } \\
\text { em alta intensidade. }\end{array}$ & $\begin{array}{l}\text { Grito de Uhhhhh, vibrações inten- } \\
\text { sas, Mulata bossa nova, xieiras, } \\
\text { xingamentos e palavras de ordem } \\
\text { como Ei [jogador adversário, institui- } \\
\text { ção ou juiz], vai tomar no cu e bicha }\end{array}$ \\
\hline
\end{tabular}

Tabela 1: Resumo das técnicas sônicas 
O decisivo nestas dinâmicas temporais da partida de futebol parece ser a percepção de qual é o momento mais apropriado, ou em que se torna necessário introduzir uma mudança rítmica. O jogo entre o Galo e o Atlas, do México, válido pela fase classificatória da Copa Liberdadores de 2015, evidencia esta busca por atuar sobre os eventos da partida por meio da introdução de transformações de andamento por meio da alternância das quatro técnicas sônicas. Esta partida se mostrava difícil, com os mexicanos demonstrando uma aplicação tática defensiva que impedia o avanço alvinegro. Além disso, a equipe mineira não havia ainda demonstrado desempenho satisfatório no ano, o que deixava a torcida desconfiada e ansiosa por um bom resultado e atuação. Aos 30 minutos do primeiro tempo, um atacante atleticano arrisca um chute de longa distância que um zagueiro adversário intercepta de cabeça. O desvio quase engana o goleiro rival e a bola sai em linha de fundo perigosamente, à esquerda do gol. Antevendo um lance de perigo no escanteio que se avizinha, a Galoucura incrementa a intensidade da música Atlético, gostamos muito de você que cantava, sendo ouvida por toda a arquibancada que harmoniza-se com a canção, passando a entoá-la. Inclusive, outro grupo torcedor, - Movimento 105, deixa de cantar seus versos - Vamos Galo, inspirado nos cânticos das barras argentinas - e assume os da torcida organizada. Apesar do cruzamento que segue não ser bem executado, passando por toda a extensão da área sem tocar em qualquer atleta e saindo novamente pela linha de fundo, o público mantém-se intensamente na canção por um minuto. A mudança rítmica não surte o efeito esperado de manter o Galo pressionando o Atlas, que na sequência vai ao ataque e consegue também um escanteio. O público percebe a necessidade de uma nova mudança rítmica e tenta produzir um novo estado de inércia, passando os dois minutos seguintes entre vaias e xieiras que configuram tortura sônica. O movimento 105 até busca retomar o Atlético, gostamos muito de você, mas sem sucesso em alastrá-lo por todo o estádio, já que o momento da partida demandava outra toada.

Esta partida contra o Atlas demonstra a importância da variação rítmica da torcida e da equipe para que estes cheguem ao seu objetivo de vitória, evidenciando limites na eficácia das técnicas de aceleração, desaceleração, inércia e tortura sônica. A postura defensiva dos mexicanos segurou o ímpeto ofensivo do Atlético durante os 90 minutos de jogo, tornando possível o gol dos visitantes que selou o placar desfavorável em um gol para os mineiros. O toque de bola lateral buscando espaços para penetração na defesa adversária produziu poucas oportunidades de gol, e com isso um pequeno número de oportunidades de tortura sônica. Além disso, estes raros momentos de acréscimo de intensidade - sonora e de performance atlética - não foram eficientes para impactar os jogadores do Atlas e quebrar o esquema tático defensivo rival. Assim, a inércia de canções como o Galoôô, Dá-Ihe Galo, Vai pra cima deles Galo e Ganhar Libertadores, tão insistentes na ocasião, ao invés de sufocar o adversário, "cozinharam" o próprio Galo em seus domínios. 


\section{CONSIDERAÇÕES FINAIS}

Neste artigo, buscamos explorar as relações temporais da disputa futebolística, procurando evidenciar como o controle da passagem do tempo e das mudanças de andamento da partida - o que introduz transformações rítmicas a partir de eventos e lances do jogo - tanto por parte dos jogadores quanto da torcida, são fundamentais para a construção do resultado esportivo. Nestas dinâmicas, certos agentes desempenham papéis específicos, como as torcidas organizadas que assumem a função de maestro da arquibancada, a ocupar um espaço privilegiado na proposta do que o público deve cantar a cada momento da disputa. Evidencia-se também uma negociação e confronto entre grupos uniformizados pela sonoridade do estádio, na medida em que parte da eficácia das técnicas de aceleração, desaceleração, inércia e tortura sônica aqui delineadas envolve diferentes potencialidades destes coletivos em realizar o contágio dos demais torcedores com seus cânticos e, por conseguinte, afetos, valores e desejos produzindo o uníssono com o qual costuma-se descrever a atuação dos torcedores de futebol no estádio. Neste processo, torcida e jogo constituem-se mutuamente no espetáculo futebolístico. Para tanto, é imprescindível que os atores - atletas, torcedores, arbitragem envolvidos na prática esportiva desenvolvam um estado de atenção corporificada obtido a partir de uma pedagogia dos sentidos introjetada por meio da contínua experiência no esporte. Assim, estes agentes aprendem que atitudes tomar de acordo com a oportunidade, a fim de alcançar conquistas, tomar as decisões corretas ou empurrar a equipe do coração rumo a seus objetivos.

\section{REFERÊNCIAS BIBLIOGRÁFICAS}

Almeida, C., Lauria, V. \& Lima, C. (2016). Evolução dos esquemas táticos no futebol. Revela, 20, 1-12.

Cusick, S. (2006). Music as torture / Music as weapon. TRANS - Revista Transcultural de Música, 10. Retirado de http://www.sibetrans.com/trans/articulo/153/la-musica-como-tortura-la-musica-como-arma

Daughtry, M. (2014). Thanatosonics: ontologies of acoustic violence. Social Text, 32(2-119), 25-52.

Daughtry, M. (2015) Listening to war. Sound, music, trauma, and survival in wartime Iraq. Nova lorque: Oxford University Press.

DeNora, T. (2000). Music in everyday life. Cambridge: Cambridge University Press.

Faulkner, R. \& Becker, H. (2009). Do you know...? The jazz repertoire in action. Chicago: University of Chicago Press.

Franco Júnior, H. (2007). A dança dos deuses: futebol, sociedade, cultura. São Paulo: Companhia das Letras.

Gumbrecht, H. (2007). Elogio da beleza atlética. São Paulo: Companhia das Letras.

Gumbrecht, H. (2014). Dança dionisíaca? Estilos nacionais no futebol sul americano. Projeto História, 49, 157-164.

Lefebvre, H. (2013). Rhythmanalysis: space, time and everyday life. Nova lorque: Bloomsbury. 
Machado, J., Barreira, D. \& Garganta, J. (2013) Eficácia ofensiva e variabilidade de padrões de jogo em futebol. Revista Brasileira de Educação Física e Esporte, 27(4), 667-677.

Marra, P. (2015). Fascínio nas arquibancadas: apontamentos metodológicos para uma cartografia dos afetos, materialidades sonoras e produção de presença na prática esportiva. In R. Helal \& F. Amaro (Eds.), Esporte e mídia: novas perspectivas: a influência da obra de Hans Ulrich Gumbrecht (pp. 201-231). Rio de Janeiro: EdUERJ.

Seel, M. (2014). No escopo da experiência estética. In B. Picado, C. Mendonça \& J. Filho (Eds.), Experiência estética e performance (pp. 23-36). Salvador: EDUFBA.

Telles, M. (2014). O replay na teletransmissão esportiva a partir do "tempo morto" do futebol. Mediação, $16(18), 61-76$.

Telles, M. \& Silva, A. (2014). Os tempos mortos do futebol na televisão. E-compós, 17(3), 1-16. Retirado de http://www.e-compos.org.br/e-compos/article/view/1167

Thompson, M. \& Biddle, I. (2013). Sound, music, affect: theorizing sonic experience. Nova lorque: Bloomsbury.

Travassos, B., Monteiro, R., Duarte, R. \& Marques, P. (2015). Sucesso defensivo no futebol: análise de tendências espácio-temporais. Centro de Pesquisa e Desenvolvimento Desportivo. Retirado de http:// formacao.comiteolimpicoportugal.pt/PremiosCOP/COP_PFO_TS/fileo27.pdf

Wilson, J. (2008). Inverting the pyramid. A history of football tactics. Londres: Orion Books.

Wisnik, J. (2008). Veneno remédio: O futebol no Brasil. São Paulo: Companhia das Letras.

\section{NOTA BIOGRÁFICA}

Pedro Silva Marra é professor do Departamento de Comunicação Social da Universidade Federal do Espírito Santo, Brasil, onde coordena o grupo de pesquisa Ateliê de Sonoridades Urbanas. Graduado em Comunicação Social, tem habilitação em jornalismo, pela Universidade Federal de Minas Gerais e é Mestre em Comunicação e Sociabilidade pela mesma instituição. Doutor em Comunicação Social pela Universidade Federal Fluminense, com estágio de pesquisa no Departamento de História da Arte e Mídia da McGill University, em Montreal, Canadá.

E-mail: pedromarra@gmail.com

Morada: Universidade Federal do Espírito Santo, Av. Fernando Ferrari, 514, Goiabeiras, CEP 29075-910 Vitória / ES (Brasil)

\section{* Submetido: 30-11-2017}

* Aceite: 15-02-2018 